\title{
THE QUANTITATIVE COLOUR TELEVISION IMAGE ANALYSER
}

\author{
A New Method of Measuring Bone Density
}

\author{
R. A. Dickson, F. Paice and J. S. Calnan, London, England \\ From the Department of Surgery and the Medical Research Council Cyclotron Unit, \\ Royal Postgraduate Medical School, London
}

There are two basic radiological methods for measuring the amount of bone tissue in the skeleton (Exton-Smith, Millard, Payne and Wheeler 1969): either by the measurement of the density of the radiographic image cast by the bone (densitometry) or by the measurement of bone dimensions.

Ever since 1901, when the first step-wedge was used to determine bone radio-opacity (Price 1901), methods have become more complicated, more expensive and vastly more timeconsuming. This paper introduces a totally new method of measuring bone density using the

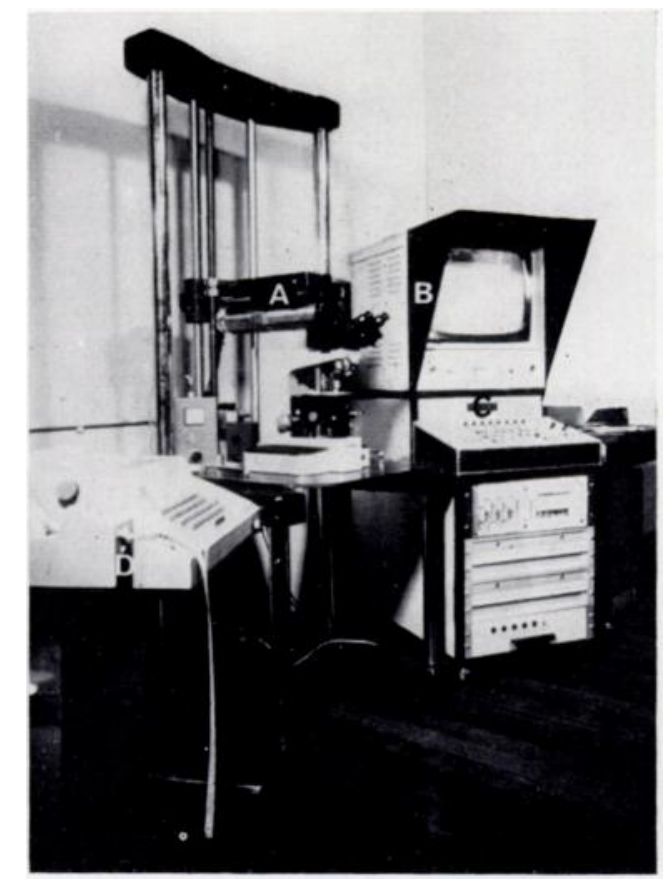

Fig. 1

The quantitative colour television image analyser.

quantitative colour television image analyser developed by M. B. Coyne and F. Paice of the Medical Research Council Cyclotron Unit, which is much more accurate and less timeconsuming.

\section{EQUIPMENT AND METHOD}

The analyser (Fig. 1) converts seven shades of grey in an optical image into seven characteristic colours. The object is viewed by a black and white television camera (A) and 
the image is displayed on a colour monitor (B), the colours on this image being related to the light intensity at each part of the object and not to its actual colour. A seven colour densitycontour map is thus presented on the screen of the monitor. Certain characteristics of the regions of equal density are determined by electronic processing, are digitally displayed (C) and may be recorded on punched tape (D) for subsequent computer analysis. One such characteristic is the total area of the regions of each density.

With the use of this equipment, changes in bone density were studied in the twenty hands of ten patients with rheumatoid disease during the year before prosthetic joint replacements.

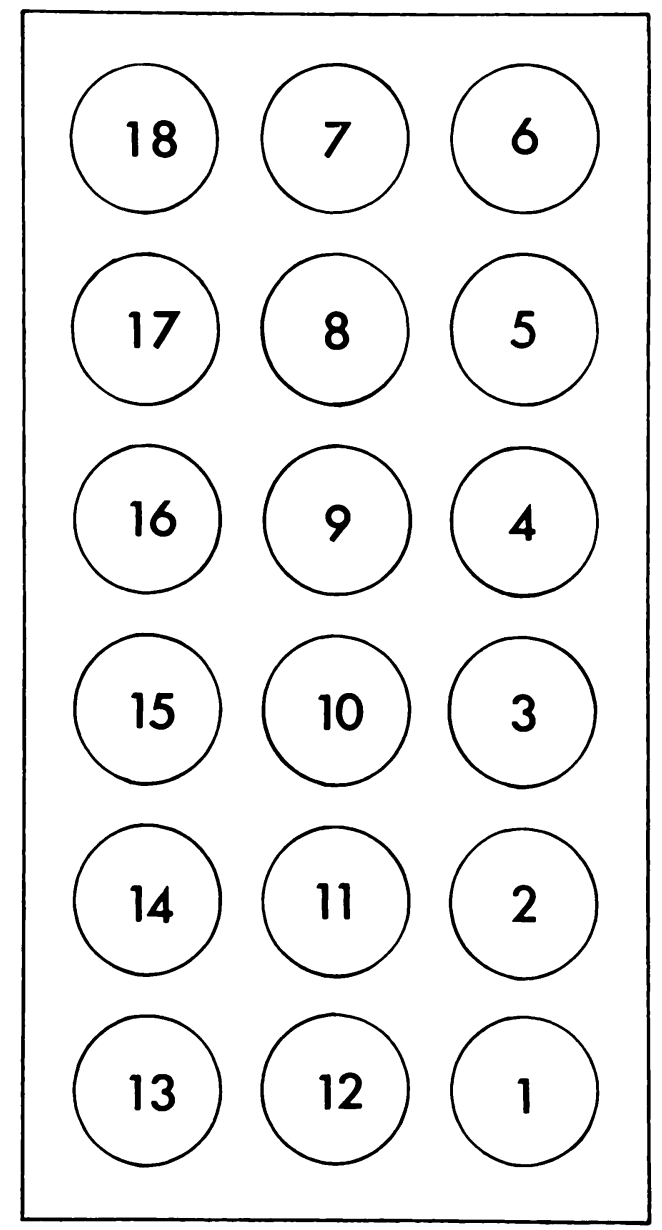

FIG. 2

A diagram to show the convention of the order of numbers of the ivory step-wedges.

Measurement of bone density-The hands of these patients were radiographed with the reference step-wedge as described and used by Bywaters (1948). This allows comparison between films, because any change in exposure and contrast affects the wedge equally as it does the bones. The wedge comprises eighteen ivory discs of graded thickness from 1 to 18 millimetres, as shown in Figure 2. Density variation in a given bone was found to be covered adequately by seven consecutive steps. If the image analyser is now tuned to these seven steps, each will have a different colour-blue, green, red, cyan, yellow, magenta and white-in that order, blue representing the most dense region in the field. When the radiograph of the bone and wedge 
is viewed, the seven different colours appear in the bone as a seven colour density-contour map (Fig. 3). The equipment will then measure the areas of each colour. By referring to the numbers on the step-wedge, the mean step position of the seven colour contour map can be quickly calculated. The result of the analysis can thus be expressed as a single number. The patient is radiographed a year later with the same ivory wedge, the analysis is repeated, and any change in bone density is apparent.

Field of measurement-Three fields were studied for each digit of both hands of every patientthe middle half of the metacarpal, the middle half of the proximal phalanx, and the metacarpophalangeal joint together with a quarter of the bone on either side (Fig. 4). In order to restrict attention to a particular field, use is made of an electronic window whose dimensions can be varied according to the size of the field to be examined. In Figure 5 the window is set on the metacarpo-phalangeal joint. All area measurements are now made within this window, to the exclusion of the remainder of the television screen.

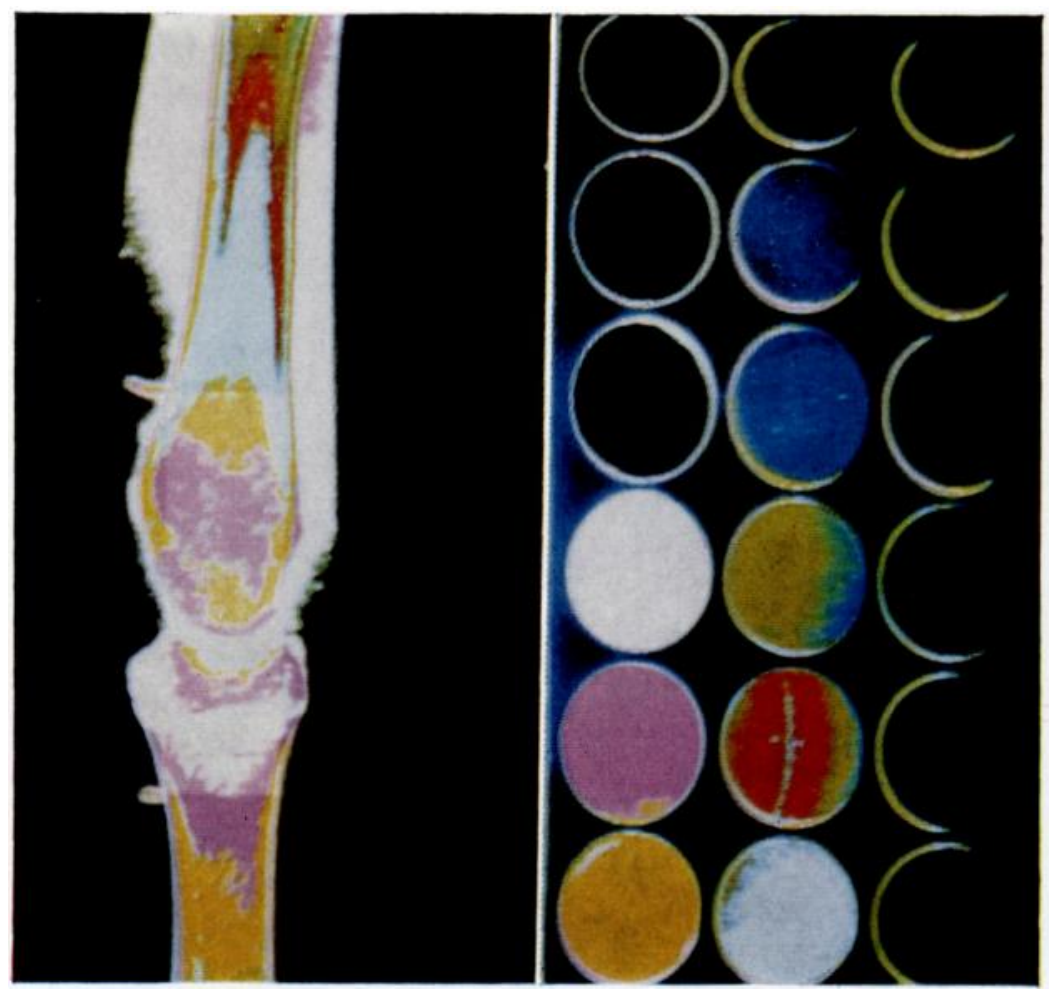

FIG. 3

A seven colour density-contour map of a digit.

Preparation of radiographs-Both the wedge and the bone must be viewed together to exclude any error due to the DC shift of the camera, when viewed individually. Furthermore, too great a separation of bone from wedge limits the accuracy by reducing magnification. In order to obtain the largest possible magnification, the radiographs are copied so that the wedge and bone can be cut out and placed closely together under the camera, in order to fill its field of view. The process of copying excludes this error and preserves the original films.

The hands of ten patients were radiographed in this manner with a wedge. A total of 240 fields were examined, and this process was repeated when comparing the films obtained one year later.

VOL. 55 B, NO. 2, MAY 1973 

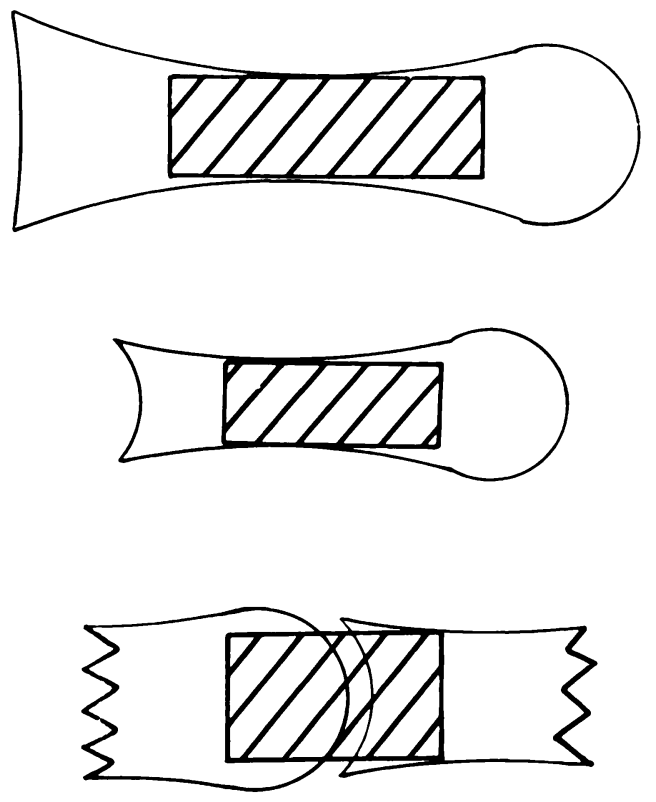

Fig. 4

A diagram to show the three positions of the window.
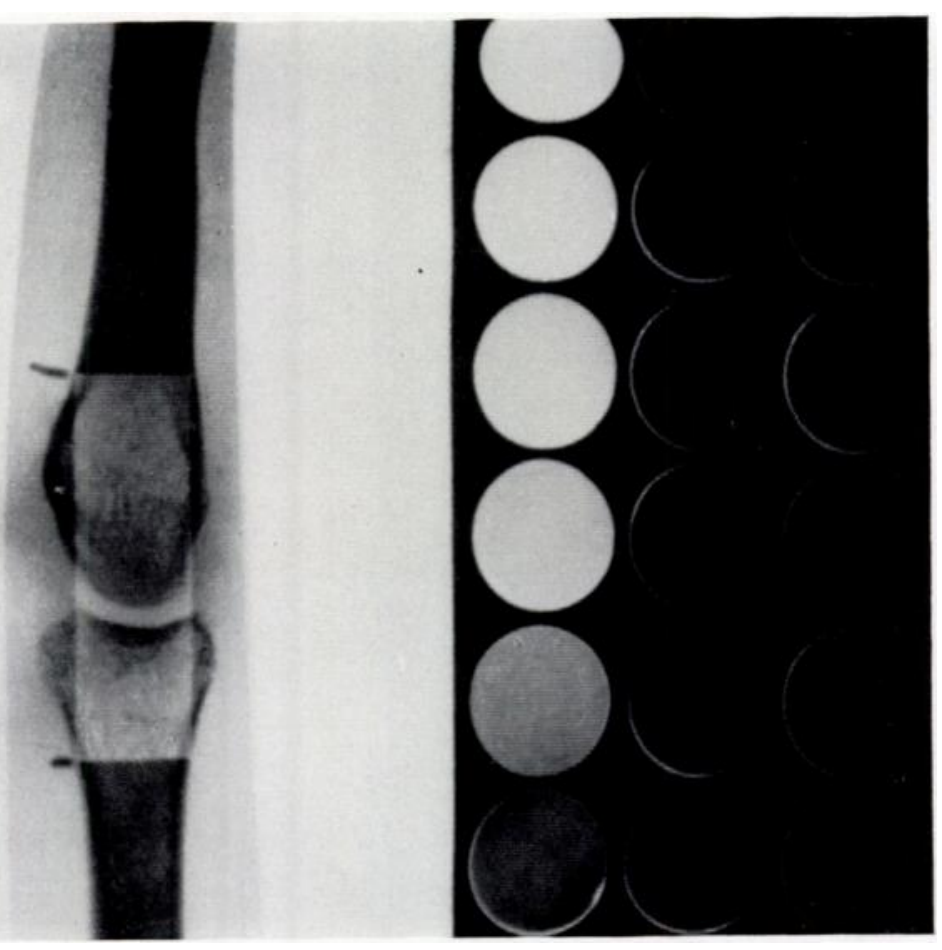

FIG. 5

The window set on a metacarpo-phalangeal joint. 


\section{RESULTS AND DISCUSSION}

Two types of bone density changes were noted, one occurring early in the progress of disease and the other associated with more advanced disease.

Early changes-The digit shown in Figure 6 illustrates the early type of bone density change in which all three fields lose bone. In this double exposure picture the upper screen shows the

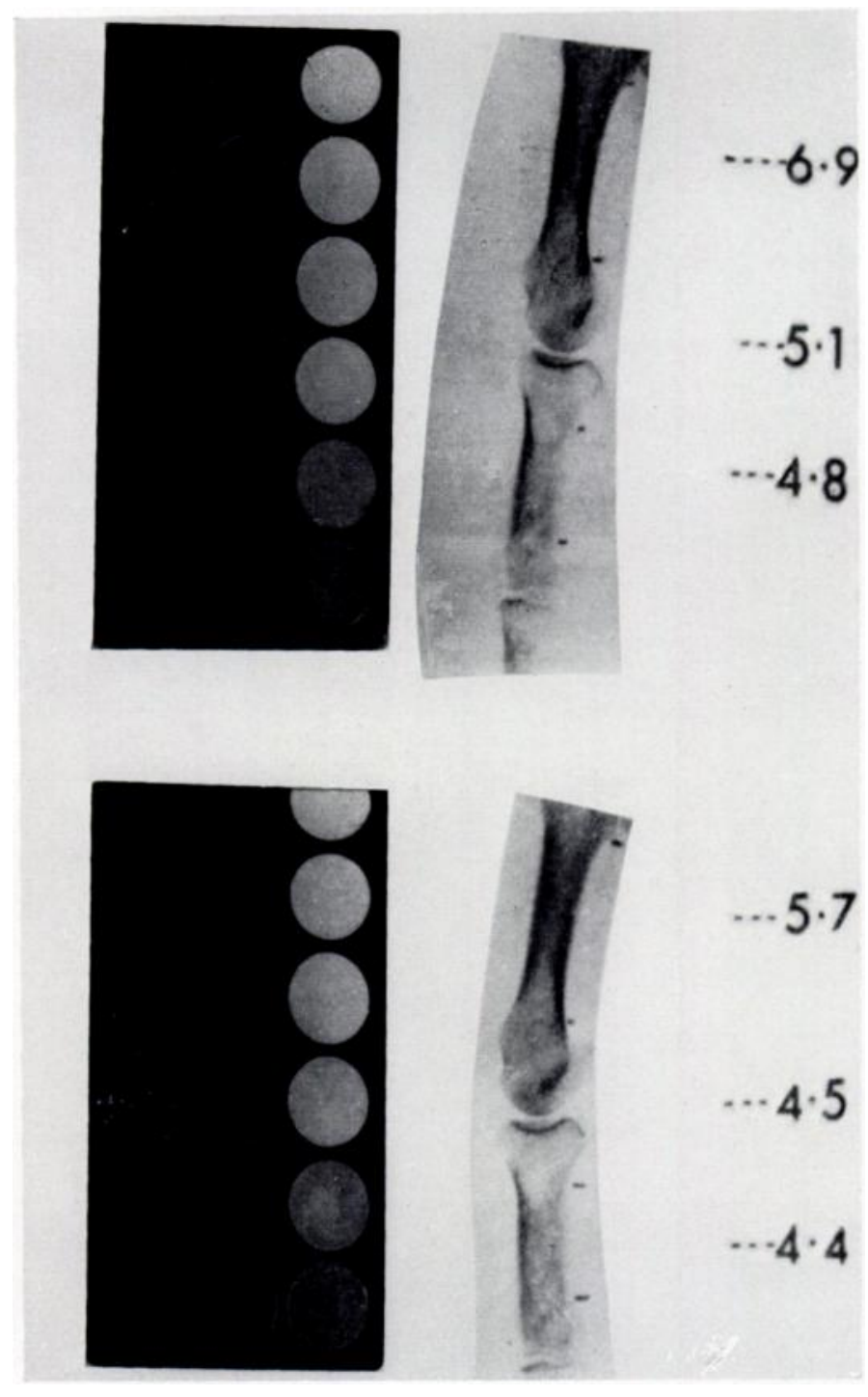

Fig. 6

A radiograph showing the early type of bone density changes-double exposure.

initial bone density measurements and the lower shows the situation one year later. Density of the metacarpal has changed from 6.9 to $5 \cdot 7$, of the joint from $5 \cdot 1$ to $4 \cdot 5$, and of the proximal phalanx from 4.8 to 4.4 . Figure 7 shows the colour television analysis of the same digit. The large area of green in the metacarpal initially, and the trace of blue, have been largely replaced by red, a colour representing a lower density. In the joint what was red before is now nearly all 
cyan-one step lower on the wedge. In order to inspect a particular density range more closely each colour can be examined individually. Taking red as an example, Figure 8 shows the same digit with all the other colours excluded; red is occupying much of the metacarpal shaft, a fair amount of the joint, and a little of the cortex of the proximal phalanx. Figure 9 shows

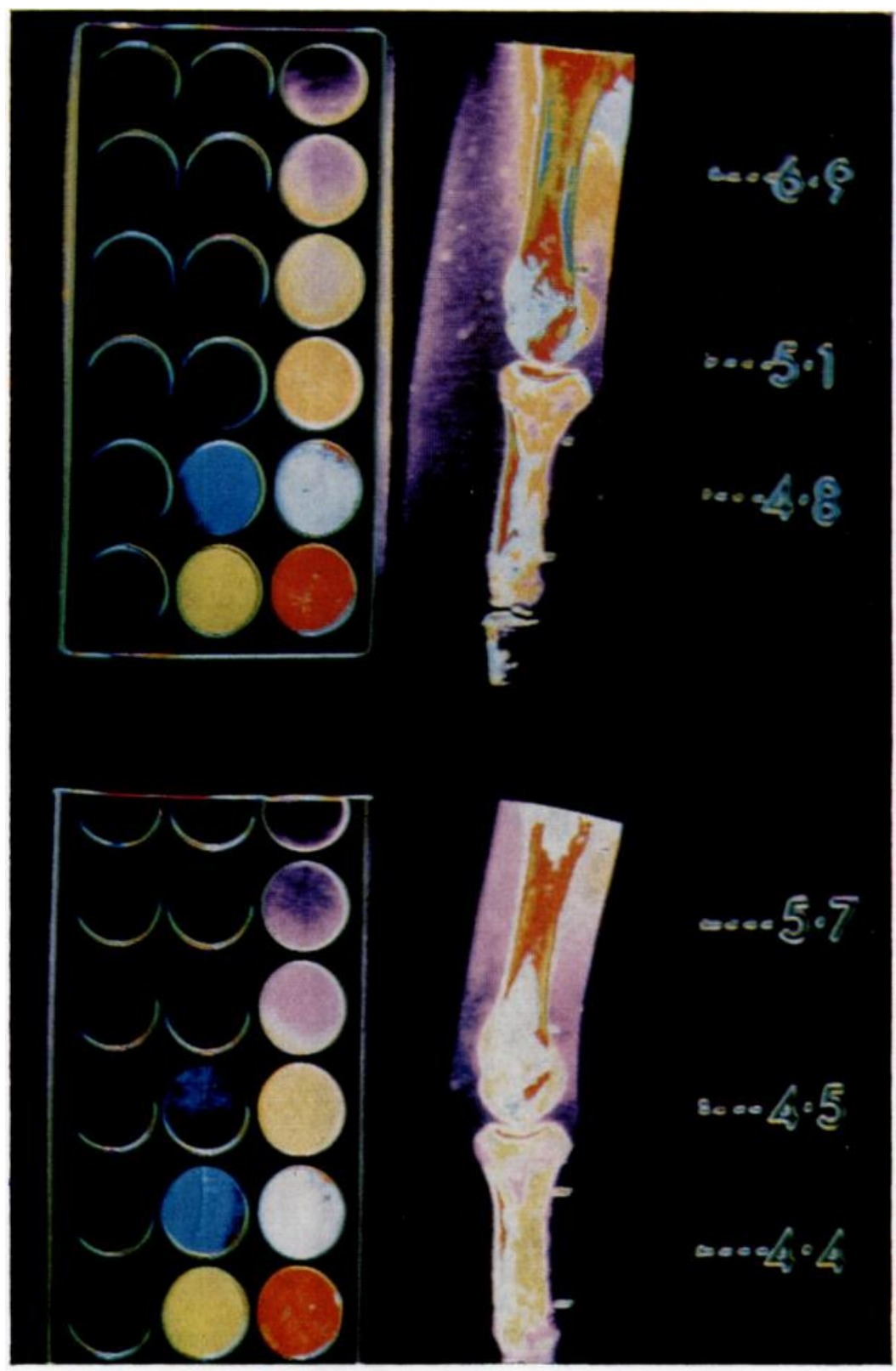

Fig. 7

The colour television analysis of early changes-double exposure.

clearly that a year later red is much reduced, and as was seen in Figure 7, its place has been taken by a colour representing a lower density.

Late changes-The digit shown in Figure 10 illustrates the late type of bone density change in which the metacarpal and proximal phalanx again lose bone, from 6.7 down to 6.3 and from 


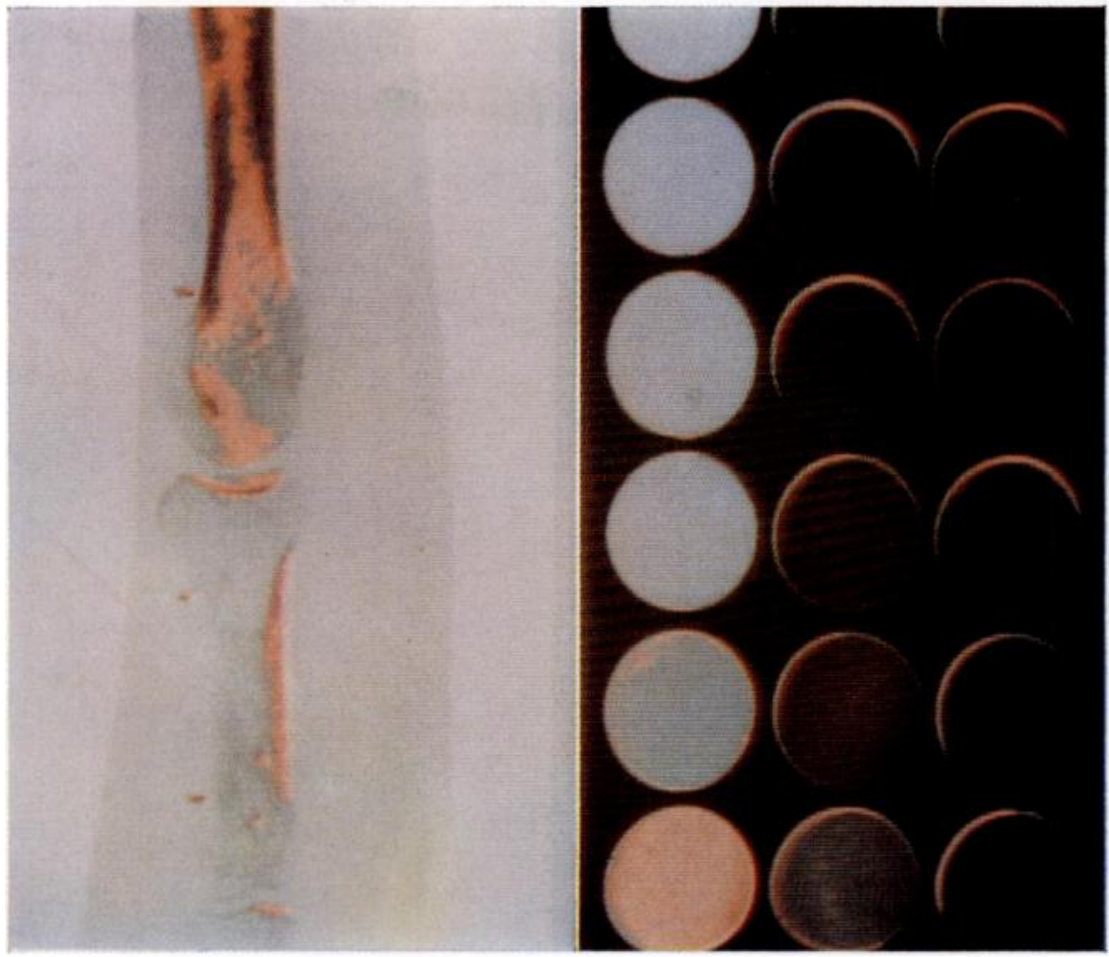

FIG. 8

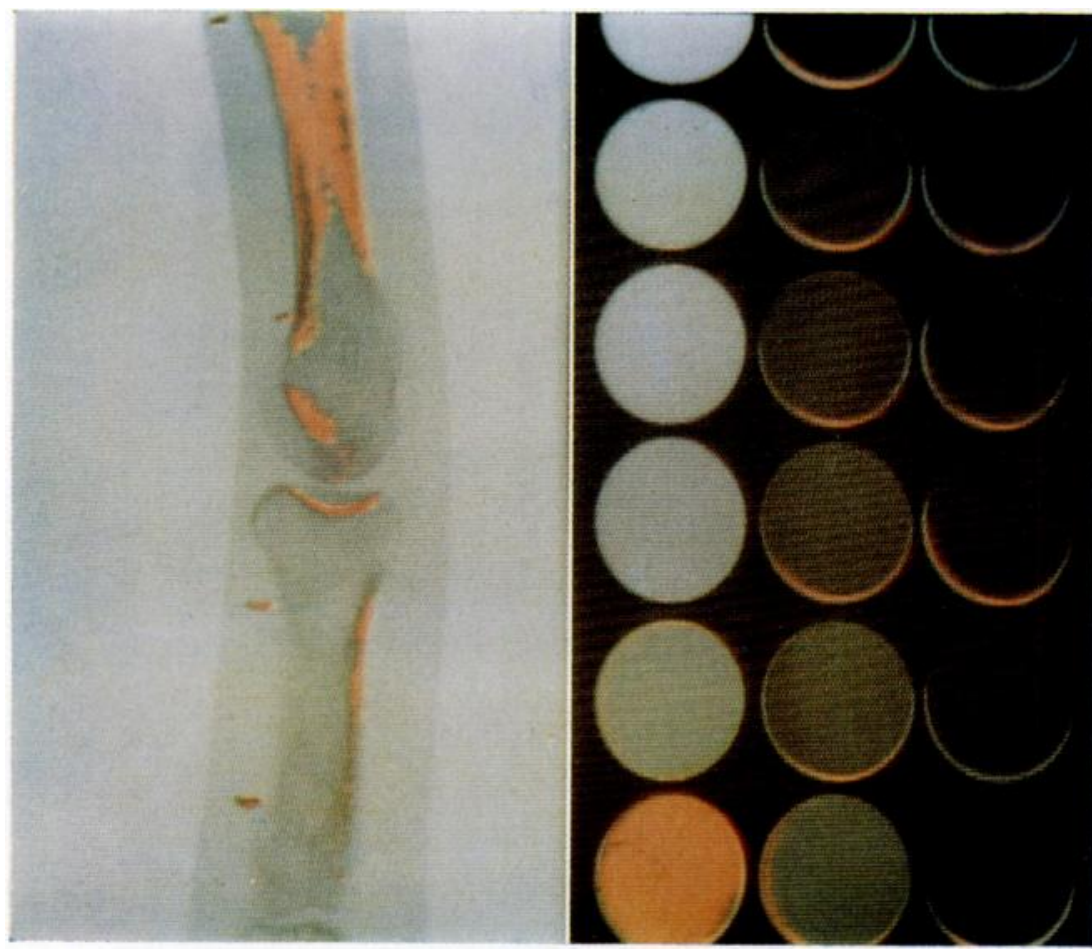

Fig. 9

Figure 8-A digit showing one density range (red) initially. Figure 9-The same digit as in Figure 8, showing one density range (red) one year later.

VOL. 55 B, NO. 2, MAY 1973 
$4 \cdot 8$ to $4 \cdot 3$ respectively, but the joint has increased in density, from $4 \cdot 7$ to $5 \cdot 3$. This has occurred because the joint has subluxed and shows some new bone growth. Figure 11 shows the colour analysis of this digit. Here it is more difficult to interpret what has happened because the colours have been tuned to different steps. However, it is clear that a reduction in density has occurred, because a year later blue has had to be set one step lower before that density zone is visualised in bone.

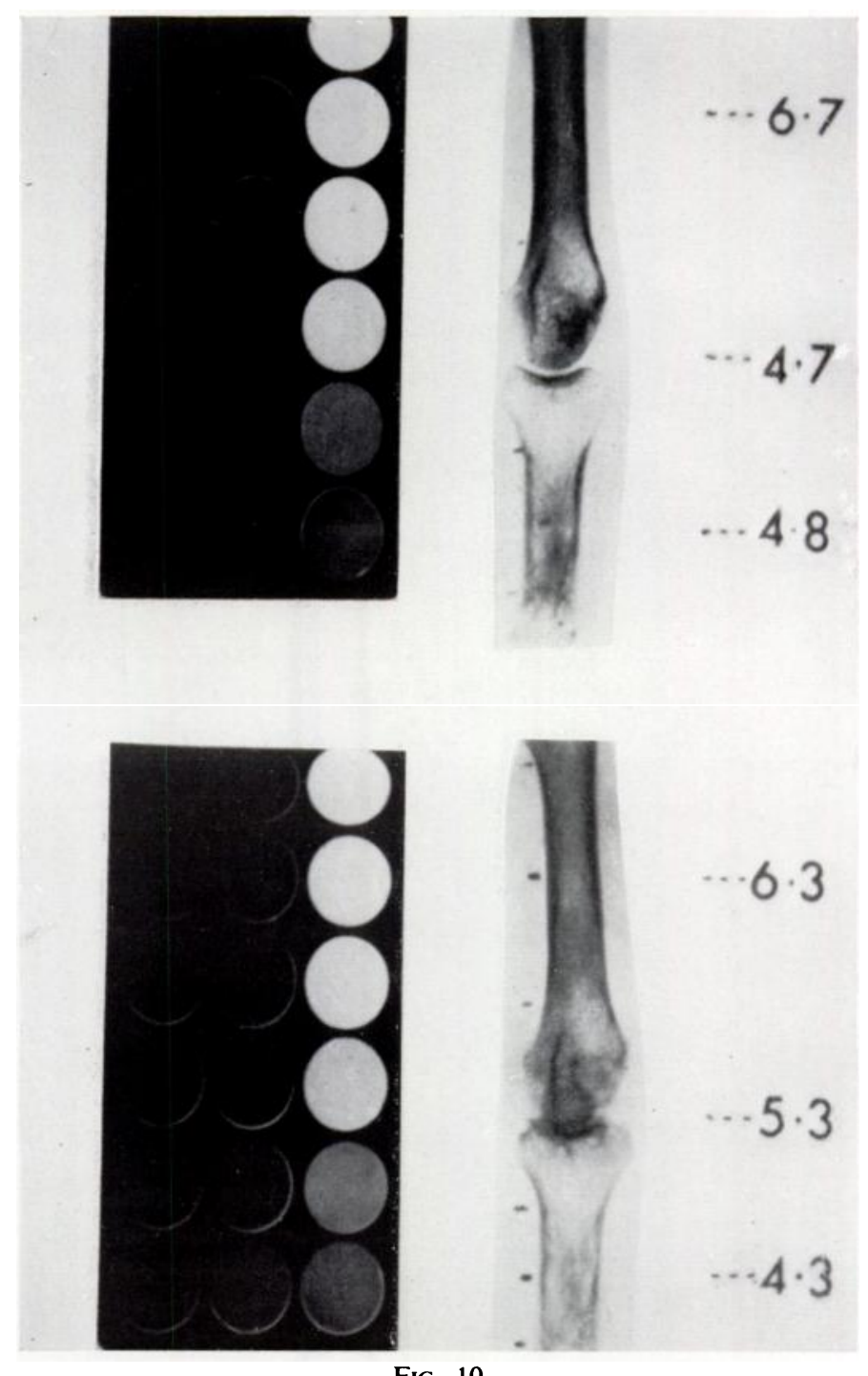

Fig. 10

A radiograph showing the late type of bone density changes-double exposure.

Figure 12 summarises the results in our ten patients. The mean annual loss of bone was $8 \cdot 3$ per cent from the joint, $9 \cdot 4$ per cent from the metacarpal and $6 \cdot 7$ per cent from the proximal phalanx. The standard deviations are large, indicating a wide range of bone loss, the maximum loss from some areas being as high as 50 per cent in one year.

These measurements have obviously included superimposed soft tissue. However, the process of copying increased the contrast and therefore the tonal separations of the step-wedge 
and the bone, the boundary between soft tissue and bone being more clearly defined, thus enabling the window to be accurately positioned. Furthermore, a change in soft-tissue density is unlikely if the soft-tissue width of the digits as measured on the original radiographs remains the same, as it did in our ten patients.

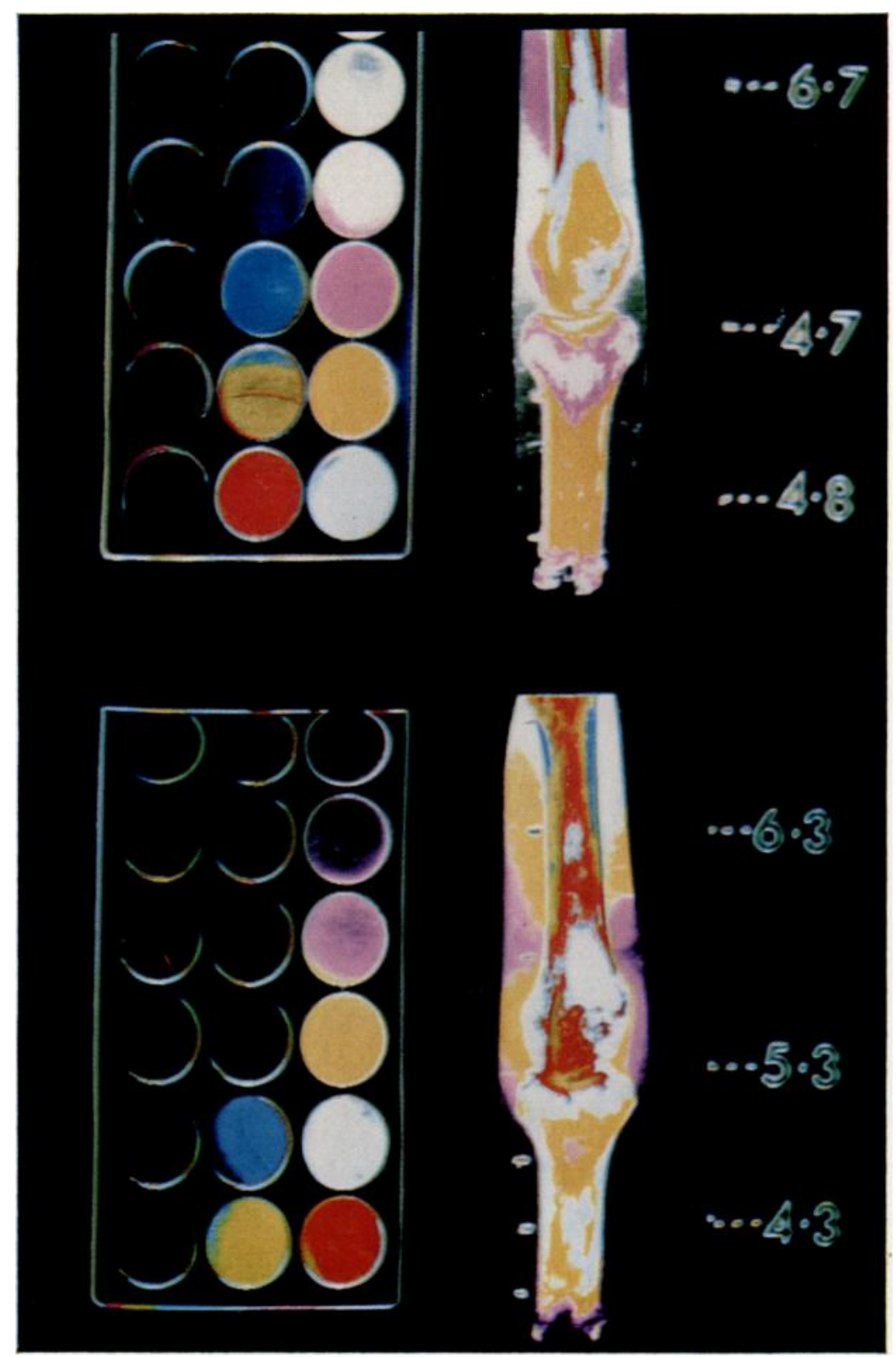

FIG. 11

Colour television analysis of the late changes-double exposure.

This method enables past radiographs to be analysed if the same wedge is present. The coefficient of variation is 1.1 per cent, which is considerably less than that associated with conventional densitometry and indicates the greater accuracy of our current technique. In addition the equipment has a multitude of other uses, from counting the number of bacterial colonies on an agar plate to measuring the surface area of a lung. 


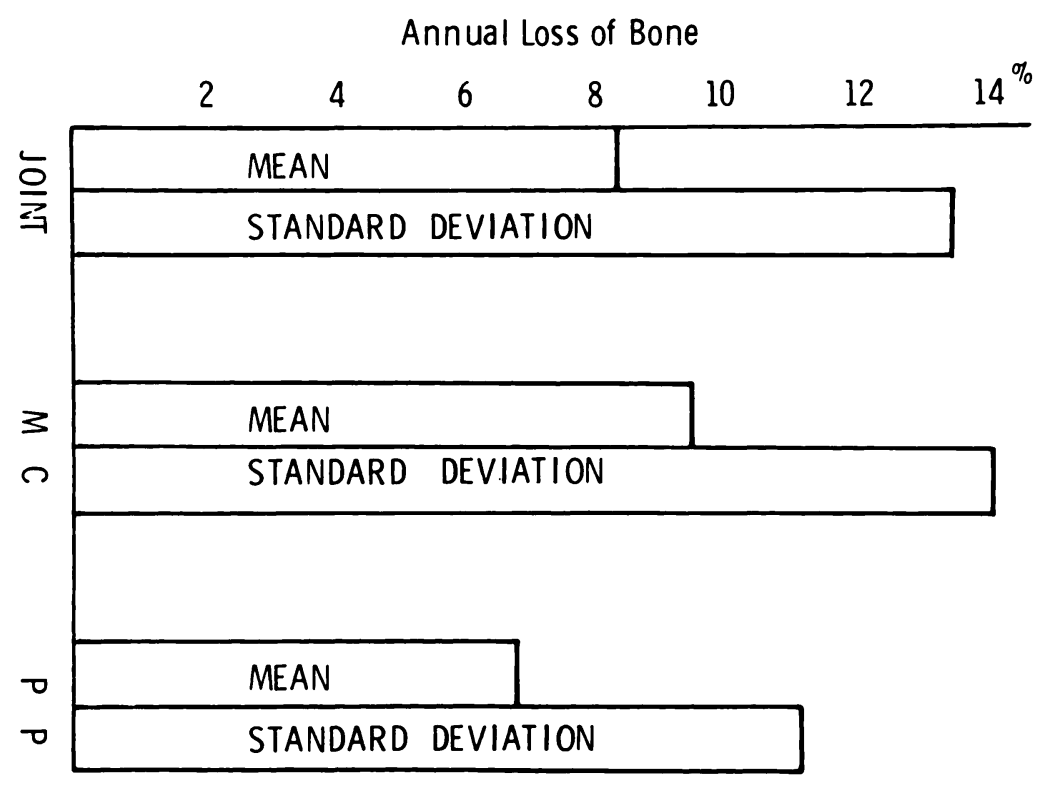

FIG. 12

A diagram to show the mean annual loss of bone expressed as a percentage, with standard deviations, from each of the three fields examined-joint, metacarpal and proximal phalanx.

\section{SUMMARY}

1. A new piece of equipment, the quantitative colour television image analyser, has been introduced as providing a superior method for measuring bone density.

2. This method produces not only a numerical result but also a pattern of density distribution in the form of a seven colour contour map.

3. The changes in twenty rheumatoid hands at an interval of one year have been measured. The metacarpals and proximal phalanges always lose bone, but the metacarpo-phalangeal joint may gain in density if the disease process is far advanced. Some areas can lose 50 per cent of bone in one year.

This study was supported by a generous grant from the Arthritis and Rheumatism Council.

\section{REFERENCES}

Bywaters, E. G. L. (1948): The Measurement of Bone Opacity. Clinical Science, 6, 281.

Exton-Smith, A. N., Millard, P. H., Payne, P. R., and Wheeler, E. F. (1969): Method for Measuring Quantity of Bone. Lancet, 2, 1153.

Price, W. A. (1901): The Science of Dental Radiography. Dental Cosmos, 43, 483. 